\title{
Clinical and pathological outcomes after resection of intramedullary spinal cord tumors: a single-institution case series
}

\author{
*Nardin Samuel, BScPharm, MSc, ${ }^{1}$ Lindsay Tetreault, PhD, ${ }^{2}$ Carlo Santaguida, MD, ${ }^{2}$ \\ Anick Nater, MD, ${ }^{3,4}$ Nizar Moayeri, MD, PhD, ${ }^{2,6}$ Eric M. Massicotte, MD, MSc, ${ }^{2,4}$ and \\ Michael G. Fehlings, MD, PhD, FRCSC ${ }^{3-6}$
}

${ }^{1}$ Faculty of Medicine, University of Toronto; ${ }^{2}$ Division of Neurosurgery, University Health Network, University of Toronto; ${ }^{3}$ Institute of Medical Sciences, Faculty of Medicine, University of Toronto; ${ }^{4}$ Department of Surgery, Division of Neurosurgery, University of Toronto; ${ }^{5}$ Department of Genetics and Development, Toronto Western Hospital; and ${ }^{6} \mathrm{Krembil}$ Neuroscience Centre, University Health Network, Toronto, Ontario, Canada

OBJECTIVE The objective of this study was to identify clinically relevant predictors of progression-free survival and functional outcomes in patients who underwent surgery for intramedullary spinal cord tumors (ISCTs).

METHODS An institutional spinal tumor registry and billing records were reviewed to identify adult patients who underwent resection of ISCTs between 1993 and 2014. Extensive data were collected from patient charts and operative notes, including demographic information, extent of resection, tumor pathology, and functional and oncological outcomes. Survival analysis was used to determine important predictors of progression-free survival. Logistic regression analysis was used to evaluate the association between an "optimal" functional outcome on the Frankel or McCormick scale at 1-year follow-up and various clinical and surgical characteristics.

RESULTS The consecutive case series consisted of 63 patients ( $50.79 \%$ female) who underwent resection of ISCTs. The mean age of patients was $41.92 \pm 14.36$ years (range 17.60-75.40 years). Complete microsurgical resection, defined as no evidence of tumor on initial postoperative imaging, was achieved in 34 cases $(54.84 \%)$ of the 62 patients for whom this information was available. On univariate analysis, the most significant predictor of progression-free survival was tumor histology $(p=0.0027)$. Patients with Grade I/II astrocytomas were more likely to have tumor progression than patients with WHO Grade II ependymomas (HR 8.03, 95\% Cl 2.07-31.11, p = 0.0026) and myxopapillary ependymomas (HR 8.01, 95\% Cl 1.44-44.34, $p=0.017$ ). Furthermore, patients who underwent radical or subtotal resection were more likely to have tumor progression than those who underwent complete resection (HR 3.46, 95\% Cl 1.23-9.73, $p=0.018$ ). Multivariate analysis revealed that tumor pathology was the only significant predictor of tumor progression. On univariate analysis, the most significant predictors of an "optimal" outcome on the Frankel scale were age $(\mathrm{OR} 0.94,95 \% \mathrm{Cl}$ $0.89-0.98, p=0.0062$ ), preoperative Frankel grade (OR 4.84, 95\% Cl 1.33-17.63, $p=0.017$ ), McCormick score (OR $0.22,95 \% \mathrm{Cl} 0.084-0.57, \mathrm{p}=0.0018$ ), and region of spinal cord (cervical vs conus: OR $0.067,95 \% \mathrm{Cl} 0.012-0.38, p=$ 0.0023 ; and thoracic vs conus: OR 0.015: $95 \% \mathrm{Cl} 0.001-0.20, \mathrm{p}=0.0013$ ). Age, tumor pathology, and region were also important predictors of 1-year McCormick scores.

CONCLUSIONS Extent of tumor resection and histopathology are significant predictors of progression-free survival following resection of ISCTs. Important predictors of functional outcomes include tumor histology, region of spinal cord in which the tumor is present, age, and preoperative functional status.

http://thejns.org/doi/abs/10.3171/2016.5.FOCUS16147

KEY WORDS intramedullary primary spinal cord tumor; ependymoma; astrocytoma; survival; functional outcomes

ABBREVIATIONS CMR = complete microsurgical resection; ISCT = intramedullary spinal cord tumor; RMR = radical microsurgical resection; STR = subtotal resection; $\mathrm{VHL}=$ von Hippel-Lindau.

SUBMITTED March 31, 2016. ACCEPTED May 23, 2016.

INCLUDE WHEN CITING DOI: 10.3171/2016.5.FOCUS16147.

* Ms. Samuel and Dr. Tetreault contributed equally to this work. 
I NTRAMEDULLARY spinal cord tumors (ISCTs) comprise $2.0 \%-8.5 \%$ of all primary central nervous system lesions in both adult and pediatric patients. ${ }^{1,5}$ In adults, ependymomas are the most common ISCTs, followed by astrocytomas and hemangioblastomas. ${ }^{18}$ Early surgical intervention is favorable in patients presenting with mild neurological deficits, as it improves functional status and results in long-term survival benefits. ${ }^{7}$ Increasingly, aggressive tumor resections have been achievable due to microsurgical advances. ${ }^{5}$ However, achieving complete resection must be balanced with the risk of peri- and postoperative neurological deficits. ${ }^{7}$ Previous studies have indicated that preoperative neurological status and tumor histology are important predictors of functional outcomes, as are intraoperative monitoring, extent of resection, and adjuvant radiation therapy. ${ }^{5,6,11,22}$ The effect of other characteristics such as demographics, intraoperative factors, and postoperative findings are not well delineated. Moreover, there is a dearth of studies investigating long-term functional outcomes in patients with ISCTs. The present study provides a systematic analysis of ISCTs managed surgically by two spine surgeons at our institution and evaluates important predictors of tumor recurrence and postoperative functional outcomes.

\section{Methods \\ Study Population}

The study was approved by the Research Ethics Board of the University Health Network. Complete information was available on 63 patients who underwent resection for primary ISCTs at the Toronto Western Hospital, University Health Network, between January 1993 and December 2014. Myxopapillary ependymomas were included in the series if there was a confirmed intramedullary component of the tumor/conus involvement. While data from patients who underwent surgery prior to 2004 were collected retrospectively, data from patients who were treated after 2004 were entered consecutively into a surgical spinal registry.

\section{Surgical Procedure}

Up-front surgery was recommended to all symptomatic patients. For patients who initially presented without symptoms, surgery was undertaken only following symptomatic or radiological progression. Surgeries were performed by two surgeons, with 55 of the 63 (87.30\%) procedures performed by the senior author (M.G.F.).

\section{Data Collection}

Data collected included demographic information and preoperative neurological status as classified by the Fran$\mathrm{kel}^{8}$ and modified McCormick ${ }^{4}$ scales (Tables 1 and 2). Each patient underwent neurological examination in the postoperative period. Length of hospital stay was also recorded. Reports from staff neuropathologists and neuroradiologists were used to confirm the histopathology of the tumor and describe the postoperative MRI imaging changes, respectively. Complete microsurgical resection (CMR) refers to the absence of residual tumor on initial postoperative MRI studies, while radical microsurgical
TABLE 1. Frankel grading scale*

\begin{tabular}{cc}
\hline Grade & \multicolumn{1}{c}{ Description } \\
\hline A & Absent motor \& sensory function \\
\hline B & Sensation present; motor function absent \\
\hline C & $\begin{array}{c}\text { Sensation present; motor function present but not } \\
\text { useful (Grade 2-3/5) }\end{array}$ \\
\hline D & $\begin{array}{c}\text { Sensation present, motor function present \& useful } \\
\text { (Grade 4/5) }\end{array}$ \\
\hline E & Normal motor \& sensory function \\
\hline
\end{tabular}

\begin{abstract}
* Based on the description in Frankel et al: The value of postural reduction in the initial management of closed injuries of the spine with paraplegia and tetraplegia. I. Paraplegia 7:179-192, 1969.
\end{abstract}

resection $(\mathrm{RMR})$ describes a tumor residual of $<20 \%$ on MRI. In cases in which there was uncertainty as to whether the postoperative MRI finding represented residual tumor, intraoperative findings were taken into account. Subtotal resection (STR) was defined as an incomplete resection of the bulk tumor. Functional and neurological status at 1- and 2-year follow-ups were classified by Frankel grades and McCormick scores.

\section{Statistical Analysis}

Continuous predictors were summarized using means, medians, standard deviations, and ranges. Categorical variables were described using frequencies and percentages. Survival analysis was performed to determine key predictors of tumor progression following surgery, as evidenced by postoperative MRI. Kaplan-Meier curves were plotted for categorical variables, and log-rank tests were conducted to assess overall significance. Cox proportional hazards regression analysis was performed to compute hazard ratios, 95\% confidence intervals, and levels of significance. We explored the predictive value of general demographics (age, sex, and preoperative neurological status), tumor characteristics (spinal region, extent of tumor, and histology), and surgical factors (extent of resection, number of levels). Multivariate analysis was conducted on variables that yielded a $\mathrm{p}$ value of $<0.2$ on univariate analysis.

A secondary analysis was performed to evaluate key predictors of postoperative functional outcomes. Changes in Frankel and McCormick scores were determined by subtracting 1-year scores from preoperative scores. Lo-

\section{TABLE 2. Modified McCormick grading scale*}

\begin{tabular}{cl}
\hline Score & \multicolumn{1}{c}{ Description } \\
\hline I & Intact neurologically; normal ambulation; minimal dysesthesia \\
\hline II & Mild motor or sensory deficit; functional independence \\
\hline III & $\begin{array}{c}\text { Moderate deficit; limitation of function; independent w/ exter- } \\
\text { nal aid }\end{array}$ \\
\hline IV & Severe motor or sensory deficit; limited function; dependent \\
\hline V & Paraplegia or quadriplegia, even w/ flickering movement \\
\hline
\end{tabular}

Reproduced with permission from Constantini et al: Intramedullary spinal cord tumors in children under the age of 3 years. J Neurosurg 85:1036-1043, 1996. 

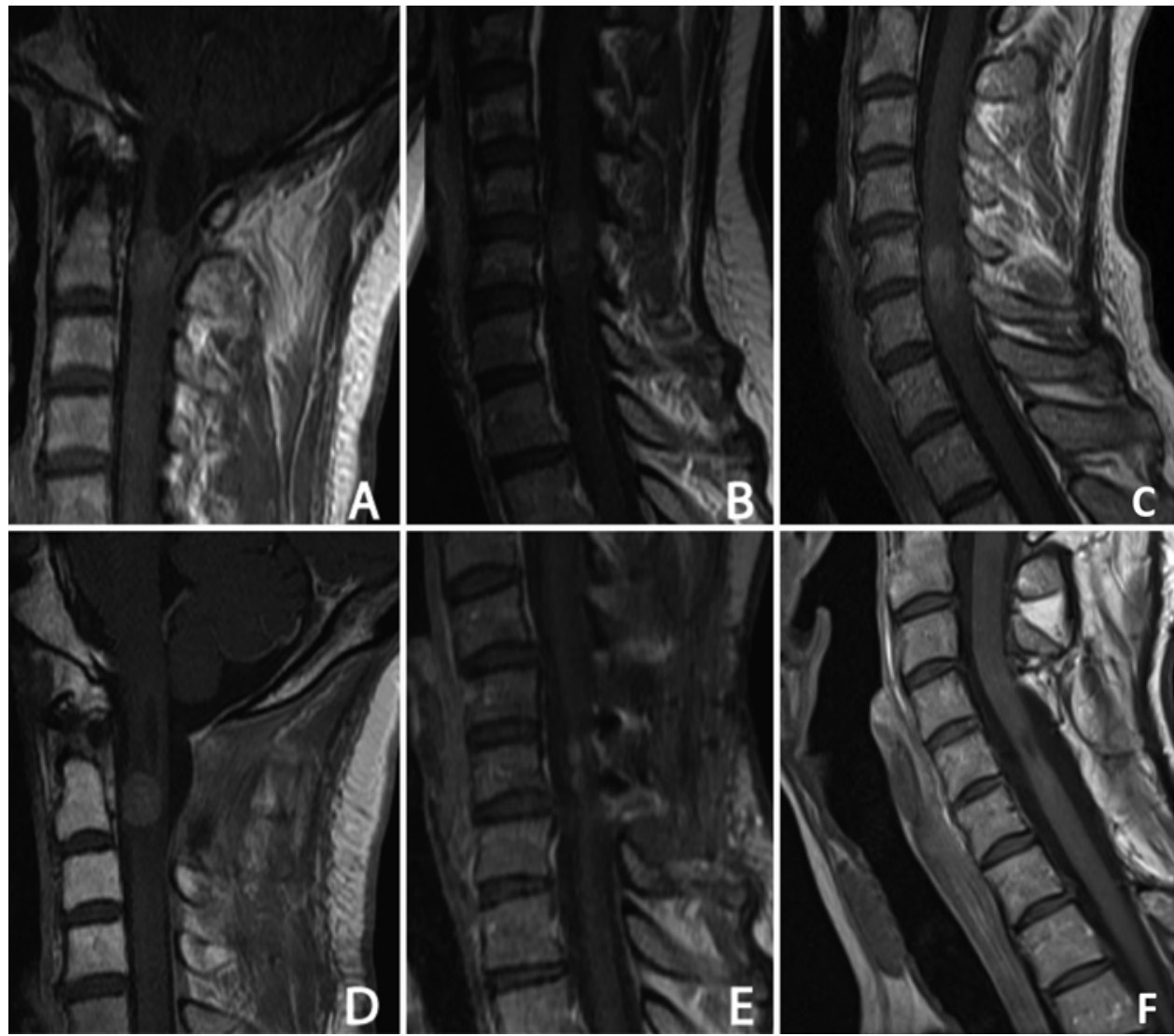

FIG. 1. Preoperative and postoperative MRI studies. A: An enhancing ISCT representing a low-grade astrocytoma centered behind the C-2 body with an associated syrinx. B: A faintly enhancing cervical ISCT representing an ependymoma. C: An enhancing cervical ependymoma. D: Postoperative image demonstrating an STR of an astrocytoma. E: Postoperative parasagittal image demonstrating a small area of enhancement that represents an RMR. F: Postoperative image demonstrating a CMR.

gistic regression analysis was used to evaluate the association between an "optimal" outcome and several demographic, tumor-related, and surgical factors. Patients were classified as having an "optimal" outcome if 1) they had a preoperative Frankel grade of C or D or a McCormick score of II, III, or IV and improved by 1 or more point or 2) they had an initial Frankel score of E or a McCormick score of I and remained stable following surgery. A "suboptimal" outcome was defined as a decline in Frankel (e.g., from D to C) or McCormick score (e.g., from II to III), or no improvement if the preoperative Frankel and McCormick scores were C or D and II, III, or IV, respectively.

\section{Results}

\section{Baseline and Surgical Characteristics}

Our series consisted of 32 (50.79\%) females and 31 (49.21\%) males, whose mean age was $41.92 \pm 14.36$ years (range 17.60-75.40 years). On initial presentation, the majority of patients presented with symptoms consistent with Frankel Grade D (73.02\%) (Table 1) and mild to moderate motor or sensory deficit, as classified using the modified McCormick Scale (Grades II-III; 71.43\%) (Table 2).

Classic ependymomas (WHO Grade II) were the most frequent tumor subtype (46.03\%) followed by myxopapillary ependymomas (17.46\%), WHO Grade I/II astrocytomas $(12.70 \%)$ and hemangioblastomas $(11.11 \%)$. Of the patients with hemangioblastomas, $42.9 \%$ (3 of 7) had known von Hippel-Lindau (VHL) syndrome. Representative imaging is shown in Fig. 1. Other pathological types included subependymomas $(3.17 \%)$, cavernous malformations (3.17\%), Grade III/IV astrocytomas (3.17\%), an oligodendroglioma (1.59\%), and a primitive neuroectodermal tumor (1.59\%); patients with these lesions were excluded from pathology risk factor analysis due to insufficient sample sizes for each histopathological classification. Tumors spanned an average of $4.65 \pm 1.67$ spinal levels (range 2-11). Twenty-nine patients $(46.03 \%)$ had a lesion located in the cervical region, $3(4.76 \%)$ in the cervicothoracic segments, $15(23.81 \%)$ in the thoracic segments, and $16(25.40 \%)$ in the conus.

The extent of resection was not available for 1 patient. A CMR was achieved in 34 of 62 cases $(54.84 \%)$, an RMR in 18 (29.03\%), and an STR in 10 (16.13\%). CMR was achieved in the majority of patients with WHO Grade II ependymomas (75.86\%), myxopapillary ependymomas (63.64\%), and hemangioblastomas (57.14\%) (Fig. 2). The median length of hospital stay following surgery was 8 days $(n=55)$. 


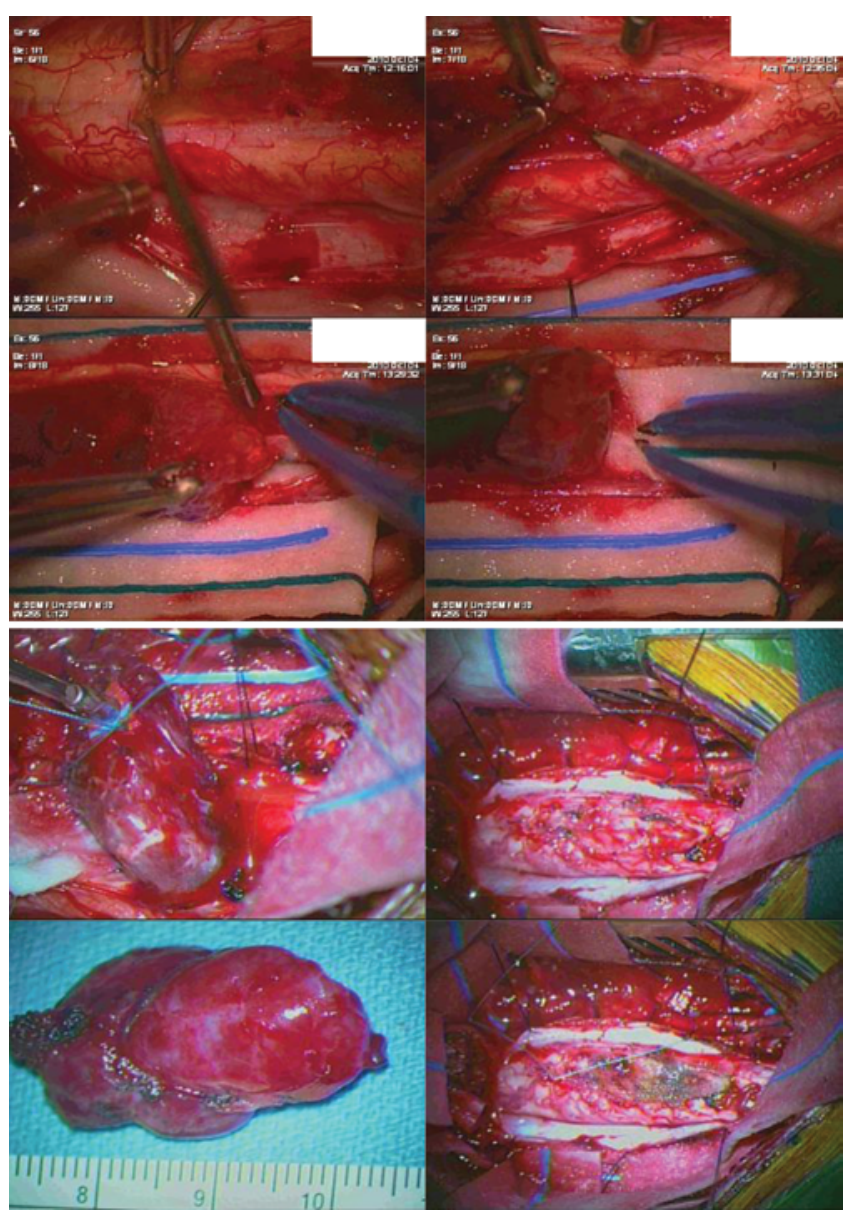

FIG. 2. Intraoperative photographs demonstrating CMR of an intramedullary ependymoma (upper) and a hemangioblastoma (lower).

\section{Predictors of Progression-Free Survival Univariate Analysis}

The results from univariate analysis are summarized in Table 3. In this series, 19 patients (30.16\%) experienced clinical and/or radiological progression of disease. There was no significant difference in age or sex between patients who did ( $38.35 \pm 12.99$ years, $57.89 \%$ male) and did not $(43.50 \pm 14.79,45.45 \%)$ experience tumor progression ( $\mathrm{p}=0.24$ and $\mathrm{p}=0.71$ for age and sex, respectively). On univariate analysis, the most significant predictor of progression-free survival was tumor histology $(p=0.0027)$ (Fig. 3). Patients with Grade I/II astrocytomas were more likely to have tumor progression than patients with WHO Grade II ependymomas (HR 8.03, 95\% CI 2.07-31.11, $\mathrm{p}=$ $0.0026)$ and myxopapillary ependymomas (HR 8.01,95\% CI $1.44-44.34, \mathrm{p}=0.017$ ). Preoperative Frankel or McCormick scores were not significant predictors of progression-free survival $(\mathrm{p}=0.11, \mathrm{p}=0.82$, respectively).

Patients who underwent radical or subtotal resection were more likely to have tumor progression than those who had a complete resection (HR 3.46, 95\% CI 1.23-9.73, $\mathrm{p}=$ $0.018)$. Extent of tumor resection ( $\mathrm{p}=0.33$ ), number of operated segments $(p=0.49)$, and region of the spine where tumor was located $(\mathrm{p}=0.32)$ were not important predictors of tumor progression.
TABLE 3. Univariate analyses evaluating the association between various clinical factors and progression-free survival

\begin{tabular}{llll}
\hline \multicolumn{1}{c}{ Predictor } & $\begin{array}{c}\text { Hazard } \\
\text { Ratio }\end{array}$ & 95\% Cl & p Value \\
\hline Histology* & & & $0.0027 \dagger$ \\
\hline Grade I/II astrocytoma & 8.03 & $2.07-31.11$ & 0.0026 \\
\hline Hemangioblastoma & 2.36 & $0.44-12.56$ & 0.31 \\
\hline Myxopapillary ependymoma & 1.00 & $0.19-5.27$ & 0.998 \\
\hline Histology $¥$ & & & $0.0027 \dagger$ \\
\hline Grade I/II astrocytoma & 8.01 & $1.44-44.34$ & 0.017 \\
\hline Hemangioblastoma & 2.36 & $0.31-17.96$ & 0.41 \\
\hline WHO Grade II ependymoma & 0.997 & $0.19-5.24$ & 0.998 \\
\hline Preop Frankel grade & 0.45 & $0.17-1.20$ & 0.11 \\
\hline Preop McCormick score & 1.29 & $0.75-2.22$ & 0.82 \\
\hline CMR vs RMR/STR & 3.46 & $1.23-9.73$ & 0.018 \\
\hline Extent of tumor & 0.85 & $0.61-1.18$ & 0.33 \\
\hline No. of operated segments & 0.89 & $0.65-1.23$ & 0.49 \\
\hline Region of spinal cord§ & & & $0.32 \dagger$ \\
\hline Cervical & 2.40 & $0.68-8.50$ & 0.18 \\
\hline Thoracic & 2.40 & $0.63-9.19$ & 0.20 \\
\hline Age & 0.98 & $0.94-1.02$ & 0.24 \\
\hline Sexף & 0.83 & $0.32-2.17$ & 0.71 \\
\hline Ref & & &
\end{tabular}

* Reference = WHO Grade II ependymoma.

$\dagger$ Significance was computed using the log-rank test.

$\ddagger$ Reference = myxopapillary ependymoma.

$\S$ Reference $=$ conus medullaris .

If Reference $=$ male.

\section{Multivariate Analysis}

Following multivariate analysis, the only significant predictor of tumor progression was tumor pathology. Although the extent of residual disease was no longer significant, tumor pathology likely encompasses this variable. In particular, surgical management of infiltrative lesions such as astrocytomas involves subtotal resection. Most importantly, patients with Grade I/II astrocytomas were at a significantly higher risk of progression than those with classic ependymomas.

\section{Predictors of Functional Outcomes at 1-Year Follow-Up}

Functional outcomes were determined based on change in Frankel and McCormick scores at 1-year follow-up; percentages are based on patients for whom sufficient clinical data were available to evaluate the Frankel and McCormick scales. Sixty patients (95.2\%) were evaluated using the Frankel and McCormick scales at 1-year follow-up. One patient (1.89\%) improved by two Frankel grades and $11(20.75 \%)$ by one grade. Scores were stable in 34 patients $(64.15 \%)$ following surgery, while in $7(13.21 \%)$ there was a decline in functional status. Based on McCormick scores, one (1.89\%) patient improved by 3 points and 17 (32.08\%) by 1 point. Twenty-three patients (43.40\%) did not exhibit improvement, while 12 (22.64\%) demonstrated a decrease in function. Twenty-two patients (41.51\%) achieved an "optimal" outcome at 1-year on the Frankel scale and 27 (50.94\%) achieved this on the McCormick scale. 

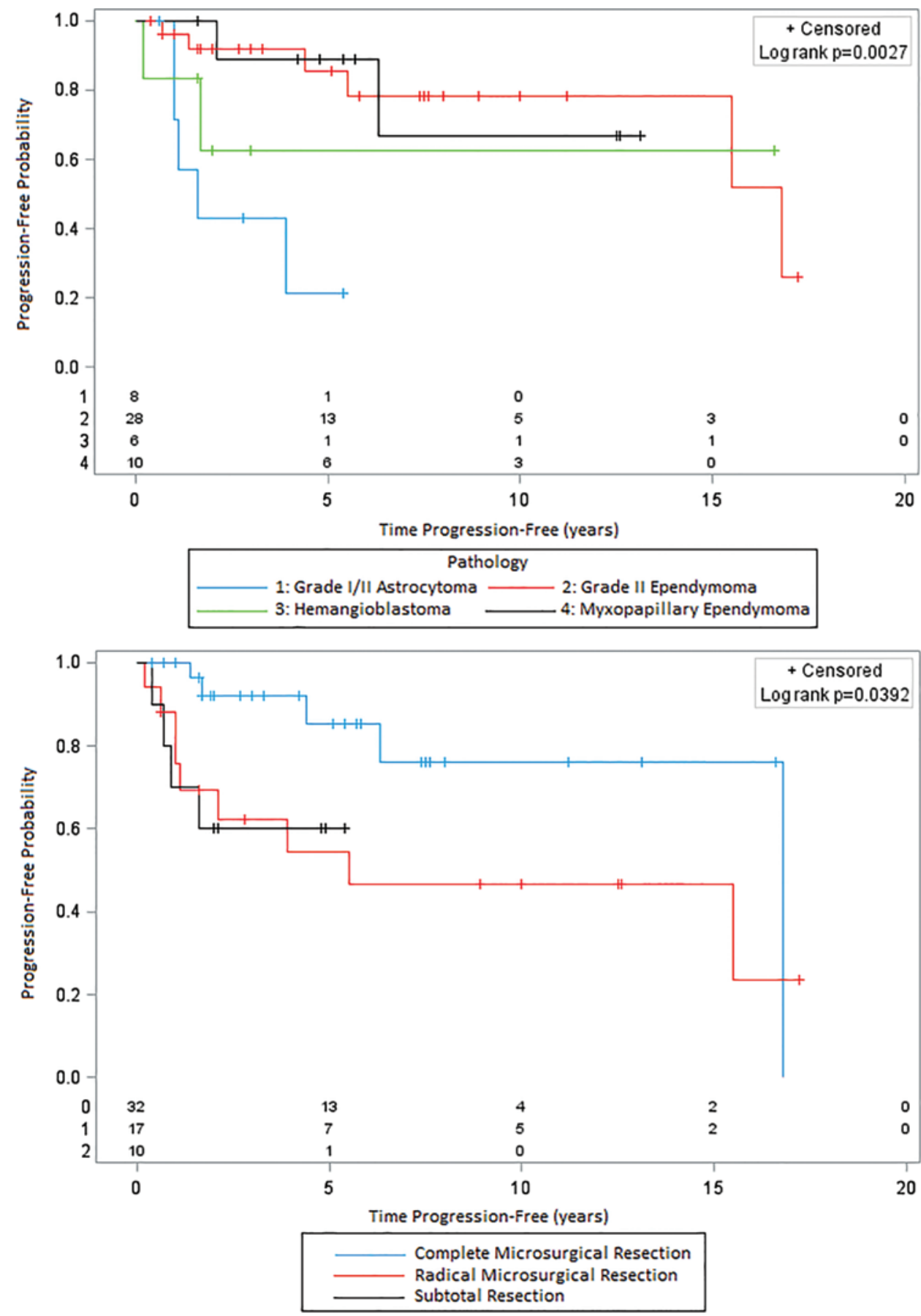

FIG. 3. Kaplan-Meier curve. The horizontal axis depicts the time to progression in years and the vertical axis depicts the probability of survival between 0 and 1 . Vertical tabs on each line denote censored data points. The numbers at the bottom reflect the number of patients at risk. Progression-free survival by tumor histology (upper) and progression-free survival by residual tumor detected on postoperative MRI (lower).

On univariate analysis, the most significant predictors of an "optimal" outcome on the Frankel scale were age (OR $0.94,95 \%$ CI $0.89-0.98, \mathrm{p}=0.0062)$ and preoperative Frankel (OR 4.84, 95\% CI 1.33-17.63, $\mathrm{p}=0.017)$ and McCormick (OR 0.22, 95\% CI 0.084-0.57, p = 0.0018) scores. Patients who achieved an "optimal" outcome had a greater number of decompressed levels $(5.30 \pm 2.28)$ than those who did not $(4.18 \pm 1.10)$, although this relationship did not reach statistical significance (OR 0.67, 95\% CI $0.44-1.005, \mathrm{p}=0.053)$. Patients with a tumor in the cervical (OR 0.067, 95\% CI 0.012-0.38, $\mathrm{p}=0.0023$ ) and thoracic (OR $0.015,95 \%$ CI $0.001-0.20, \mathrm{p}=0.0013$ ) regions were less likely to achieve an "optimal" outcome than patients with a tumor in the conus medullaris (Table 4). 
TABLE 4. Univariate analyses evaluating the association between various clinical factors and functional outcomes 1 year postoperatively

\begin{tabular}{|c|c|c|c|c|c|c|}
\hline \multirow[b]{2}{*}{ Predictor } & \multicolumn{3}{|c|}{ Frankel Grade } & \multicolumn{3}{|c|}{ McCormick Score } \\
\hline & Hazard Ratio & $95 \% \mathrm{Cl}$ & $p$ Value & Hazard Ratio & $95 \% \mathrm{Cl}$ & $\mathrm{p}$ Value \\
\hline Age & 0.94 & $0.89-0.98$ & 0.0062 & 0.94 & $0.90-0.98$ & 0.0045 \\
\hline Preop Frankel grade & 4.84 & $1.33-17.63$ & 0.017 & 1.56 & $0.51-4.79$ & 0.44 \\
\hline Preop McCormick score & 0.22 & $0.084-0.57$ & 0.0018 & 0.72 & $0.37-1.38$ & 0.32 \\
\hline No. of levels decompressed & 0.67 & $0.44-1.005$ & 0.053 & 1.03 & $0.78-1.37$ & 0.83 \\
\hline Extent of tumor & 0.73 & $0.49-1.08$ & 0.12 & 1.12 & $0.80-1.57$ & 0.49 \\
\hline CMR vs RMR/STR & 0.35 & $0.11-1.14$ & 0.081 & 0.50 & $0.16-1.52$ & 0.22 \\
\hline Sex* & 0.65 & $0.22-1.96$ & 0.44 & 0.80 & $0.27-2.36$ & 0.68 \\
\hline \multicolumn{7}{|l|}{ Region of spinal cord $\dagger$} \\
\hline Cervical & 0.067 & $0.012-0.38$ & 0.0023 & 0.099 & $0.018-0.55$ & 0.0079 \\
\hline Thoracic & 0.015 & $0.001-0.20$ & 0.0013 & 0.015 & $0.001-0.20$ & 0.0013 \\
\hline \multicolumn{7}{|l|}{ Histology $\ddagger$} \\
\hline Grade I/II astrocytoma & 0.037 & $0.003-0.50$ & 0.013 & 0.037 & $0.003-0.50$ & 0.013 \\
\hline Hemangioblastoma & 0.083 & $0.006-1.07$ & 0.056 & 0.15 & $0.012-1.90$ & 0.14 \\
\hline WHO Grade II ependymoma & 0.044 & $0.005-0.41$ & 0.0060 & 0.083 & $0.009-0.75$ & 0.027 \\
\hline
\end{tabular}

* Reference $=$ male.

$\uparrow$ Reference $=$ conus medullaris.

$\ddagger$ Reference = myxopapillary ependymoma.

Furthermore, patients who underwent a CMR were more likely to achieve an "optimal" outcome than patients who had a subtotal or radical resection (OR 0.35, $95 \%$ CI $0.11-1.14, p=0.081$ ); however, this association did not reach statistical significance. Sex $(p=0.44)$ was not an important predictor of postoperative Frankel outcomes. Compared with myxopapillary ependymoma, patients with WHO Grade II ependymomas (OR 0.044, $95 \%$ CI $0.005-0.41, \mathrm{p}=0.0060)$ and Grade I/II astrocytomas (OR $0.037,95 \%$ CI $0.003-0.50, \mathrm{p}=0.013$ ) were less likely to achieve an "optimal" outcome on the Frankel scale.

Using the McCormick classification, age was a significant predictor of an "optimal" outcome (OR 0.94, 95\% CI $0.90-0.98, p=0.0045)$. Tumor pathology was also significantly associated with outcomes: patients with myxopapillary ependymomas (WHO Grade I) were more likely to achieve an "optimal" outcome than patients with WHO Grade I/II astrocytomas (OR 0.037, 95\% CI 0.003-0.50, $\mathrm{p}=0.013$ ) and WHO Grade II classic ependymomas (OR $0.083,95 \%$ CI $0.009-0.75, \mathrm{p}=0.027)$. Patients with a tumor in the cervical (OR 0.099, 95\% CI 0.018-0.55, p = 0.0079 ) and thoracic (OR $0.015,95 \%$ CI $0.001-0.20, \mathrm{p}=$ $0.0013)$ regions were less likely to achieve an "optimal" outcome than patients with a tumor in the conus medullaris. Sex $(p=0.68)$, number of levels decompressed ( $p$ $=0.83)$, extent of tumor resection $(\mathrm{p}=0.49)$, and type of resection $(p=0.22)$ were not important predictors of McCormick scores. Furthermore, preoperative McCormick score $(\mathrm{p}=0.32)$ and Frankel grade $(\mathrm{p}=0.44)$ were not significantly associated with outcome.

\section{Discussion}

Resection of ISCTs is the favored first-line approach for patients presenting with neurological impairment. Ad- ditionally, as surgical techniques continue to advance, it is expected that patient outcomes will improve and that risks associated with resection will decrease. ${ }^{10}$ The present study describes a large case series in Canada and is the first review of ISCTs at our institution.

The findings from this study provide strong support that tumor histology is the most important predictor of tumor progression. On univariate analysis, residual tumor was associated with a lower rate of progression-free survival; however, all patients who underwent RMR or STR had astrocytic tumors or tumors of malignant histology. By contrast, CMR and RMR were achieved in the majority of patients with WHO Grade II ependymomas, myxopapillary ependymomas, and hemangioblastomas. This finding suggests that the relationship between extent of tumor resection and progression is likely reflective of the underlying tumor pathology. This is consistent with a published single-center case series of 102 patients surgically treated for ISCTs, ${ }^{12}$ which reported that histopathology predicts extent of resection as well as tumor recurrence. Most ependymomas have a more defined surgical plane in contrast to astrocytomas, which have no surgical plane. The presence of a tumor resection plane alone has been shown to improve progressionfree survival, irrespective of tumor histology ${ }^{9,13,21}$ However, although postoperative residual tumor is an important predictor of progression, the aggressiveness of resection should be cautiously weighed against the risk of new postoperative neurological deficit. ${ }^{3}$ Collectively, favorable histology combined with complete or radical resection favors long-term survival in patients with ISCTs.

Regarding functional outcomes, our results demonstrate that preoperative functional status, tumor histology and age are the most important predictors of stable or improved outcomes as evaluated by Frankel and McCormick scores. Patients with WHO Grade II ependymomas and myxopapillary ependymomas largely have stable immedi- 
ate postsurgical outcomes and stable or improved neurological status at 1-year follow-up. Results from a targeted case series of spinal cord ependymomas corroborate these findings. ${ }^{2}$ The majority of patients with astrocytic tumors presented with no change or a decline in neurological status at 1-year follow-up. Previous studies of malignant ISCTs have demonstrated that aggressive resection may preserve neurological function, particularly in astrocytomas; however, this may be associated with a significant risk of decline in postoperative motor function. ${ }^{16}$ Additionally, 3 patients with hemangioblastomas in our study were previously diagnosed with a genetic predisposition syndrome such as VHL syndrome. The authors of a large case series involving neurosurgical resection of hemangioblastomas in patients with VHL syndrome reported that $78 \%$ of their patients remained functionally stable during a 15-year follow-up. ${ }^{17}$ Long-term decline was usually associated with disease progression secondary to other associated lesions. Numerous studies in the literature have demonstrated significant benefits, in terms of survival and quality of life, when hemangioblastomas were resected in VHL patients. ${ }^{12,14,19,20}$

Consistent with our findings of the importance of preoperative functional status in predicting postoperative functional outcomes, a clinical systematic review of the treatment of ISCTs concluded that a patient's preoperative neurological status is the most important factor in determining long-term postoperative neurological and functional outcomes. ${ }^{11}$ In particular, improved postoperative ambulatory ability is more likely in patients with good preoperative neurological status, classified as either normal ambulation or mild motor sensory deficit with independent ambulation not requiring external aid. ${ }^{15}$ Short- and long-term postoperative functional outcomes in patients with ISCTs are likely multifactorial and additional systematic analyses are needed to further delineate the most clinically relevant and measureable predictors.

\section{Limitations}

Retrospective studies are subject to significant selection and information biases. In addition, large sample sizes are required to retrospectively study rare outcomes, such as tumor progression. Since our sample consisted of 63 patients, the confidence intervals for our estimates were wide, reflecting variability and relative imprecision. This study also did not assess the contribution of intraoperative variables to immediate and short-term neurological status. Additional studies investigating the impact of neuromonitoring and other operative parameters on outcomes for ISCTs are therefore warranted. Finally, since the modified McCormick and Frankel grading systems used in our study are relatively crude measures of outcome, future prospective studies should evaluate outcomes using more accurate measures of impairment such as the Standard for Neurological Classification of Spinal Cord Injury (SNCSCI).

\section{Conclusions}

This study demonstrates that tumor pathology is the most important predictor of progression-free survival in patients treated surgically for ISCTs. Long-term function- al outcomes are expected to be most favorable in patients with myxopapillary ependymomas, younger age, and good preoperative functional status. We anticipate the results from this study will complement other similar case series in the literature and aid in the prediction of survival and outcomes in patients with ISCTs.

\section{Acknowledgments}

Dr. Fehlings is supported by the Gerald and Tootsie Halbert Chair in Neural Repair and Regeneration and the DeZwirek Family Foundation.

\section{References}

1. Barker DJ, Weller RO, Garfield JS: Epidemiology of primary tumours of the brain and spinal cord: a regional survey in southern England. J Neurol Neurosurg Psychiatry 39:290296, 1976

2. Boström A, von Lehe M, Hartmann W, Pietsch T, Feuss M, Boström JP, et al: Surgery for spinal cord ependymomas: outcome and prognostic factors. Neurosurgery 68:302-309, 2011

3. Brotchi J: Intramedullary astrocytomas surgery in adult patients: the rationale for cautious surgery. World Neurosurg 80:e139-e140, 2013

4. Constantini S, Houten J, Miller DC, Freed D, Ozek MM, Rorke LB, et al: Intramedullary spinal cord tumors in children under the age of 3 years. J Neurosurg 85:1036-1043, 1996

5. Constantini S, Miller DC, Allen JC, Rorke LB, Freed D, Epstein FJ: Radical excision of intramedullary spinal cord tumors: surgical morbidity and long-term follow-up evaluation in 164 children and young adults. J Neurosurg 93 (2 Suppl):183-193, 2000

6. Cristante L, Herrmann HD: Surgical management of intramedullary spinal cord tumors: functional outcome and sources of morbidity. Neurosurgery 35:69-76, 1994

7. Fehlings MG, Mercier D: Factors predicting the resectability of intramedullary spinal cord tumors and the progressionfree survival following microsurgical treatment. J Neurosurg Spine 11:588-590, 2009

8. Frankel HL, Hancock DO, Hyslop G, Melzak J, Michaelis LS, Ungar GH, et al: The value of postural reduction in the initial management of closed injuries of the spine with paraplegia and tetraplegia. I. Paraplegia 7:179-192, 1969

9. Garcés-Ambrossi GL, McGirt MJ, Mehta VA, Sciubba DM, Witham TF, Bydon A, et al: Factors associated with progression-free survival and long-term neurological outcome after resection of intramedullary spinal cord tumors: analysis of 101 consecutive cases. J Neurosurg Spine 11:591-599, 2009

10. Haji FA, Cenic A, Crevier L, Murty N, Reddy K: Minimally invasive approach for the resection of spinal neoplasm. Spine (Phila Pa 1976) 36:E1018-E1026, 2011

11. Harrop JS, Ganju A, Groff M, Bilsky M: Primary intramedullary tumors of the spinal cord. Spine (Phila Pa 1976) 34 (22 Suppl):S69-S77, 2009

12. Karikari IO, Nimjee SM, Hodges TR, Cutrell E, Hughes BD, Powers CJ, et al: Impact of tumor histology on resectability and neurological outcome in primary intramedullary spinal cord tumors: a single-center experience with 102 patients. Neurosurgery 76 (Suppl 1):S4-S13, 2015

13. Klekamp J: Treatment of intramedullary tumors: analysis of surgical morbidity and long-term results. J Neurosurg Spine 19:12-26, 2013

14. Lonser RR, Weil RJ, Wanebo JE, DeVroom HL, Oldfield EH: Surgical management of spinal cord hemangioblastomas in patients with von Hippel-Lindau disease. J Neurosurg 98:106-116, 2003 
15. Matsuyama Y, Sakai Y, Katayama Y, Imagama S, Ito Z, Wakao N, et al: Surgical results of intramedullary spinal cord tumor with spinal cord monitoring to guide extent of resection. J Neurosurg Spine 10:404-413, 2009

16. McGirt MJ, Goldstein IM, Chaichana KL, Tobias ME, Kothbauer KF, Jallo GI: Extent of surgical resection of malignant astrocytomas of the spinal cord: outcome analysis of 35 patients. Neurosurgery 63:55-61, 2008

17. Mehta GU, Asthagiri AR, Bakhtian KD, Auh S, Oldfield EH, Lonser RR: Functional outcome after resection of spinal cord hemangioblastomas associated with von Hippel-Lindau disease. J Neurosurg Spine 12:233-242, 2010

18. Miller DC: Surgical pathology of intramedullary spinal cord neoplasms. J Neurooncol 47:189-194, 2000

19. Park CH, Lee CH, Hyun SJ, Jahng TA, Kim HJ, Kim KJ: Surgical outcome of spinal cord hemangioblastomas. J Korean Neurosurg Soc 52:221-227, 2012

20. Pavesi G, Feletti A, Berlucchi S, Opocher G, Martella M, Murgia A, et al: Neurosurgical treatment of von HippelLindau-associated hemangioblastomas: benefits, risks and outcome. J Neurosurg Sci 52:29-36, 2008

21. Raco A, Esposito V, Lenzi J, Piccirilli M, Delfini R, Cantore G: Long-term follow-up of intramedullary spinal cord tumors: a series of 202 cases. Neurosurgery 56:972-981, 2005

22. Samii M, Klekamp J: Surgical results of 100 intramedullary tumors in relation to accompanying syringomyelia. Neurosurgery 35:865-873, 1994

\section{Disclosures}

Dr. Massicotte reports a personal relationship with AOSpine North America.

\section{Author Contributions}

Conception and design: Fehlings. Acquisition of data: Fehlings, Santaguida, Massicotte. Analysis and interpretation of data: Samuel, Tetreault, Santaguida, Nater, Moayeri. Drafting the article: all authors. Critically revising the article: Fehlings, Samuel, Tetreault, Massicotte. Reviewed submitted version of manuscript: Samuel, Tetreault, Nater, Moayeri, Massicotte. Study supervision: Fehlings.

\section{Supplemental Information Current Affiliations}

Dr. Moayeri: Department of Neurology and Neurosurgery, Brain Center Rudolf Magnus, University Medical Center Utrecht, Utrecht, The Netherlands.

\section{Previous Presentations}

Portions of this work were presented in oral form as proceedings at the 2016 Spine Summit-32nd Annual Meeting of the Section on Disorders of the Spine and Peripheral Nerves, Orlando, Florida, March 18, 2016.

\section{Correspondence}

Michael G. Fehlings, Toronto Western Hospital, West Wing, 4th Fl., Rm. 4WW449, 399 Bathurst St., Toronto, ON M5T 2S8, Canada. email: michael.fehlings@uhn.ca. 